\title{
APLIKASI SMART INVESTMENT PLANNER BERBASIS WEB
}

\author{
Prasetya K. ${ }^{1}$; Endah K. ${ }^{2}$; Fredicia $^{3}$ \\ ${ }^{1,2,3}$ Fakultas Teknik dan Ilmu Komputer, Universitas Kristen Krida Wacana \\ Jl. Tanjung Duren Raya No.4, Jakarta Barat 11470 \\ 1skymoveable@gmail.com; '²redi.cia@ukrida.ac.id; ’endah.kristiani@ukrida.ac.id
}

\begin{abstract}
The lack of knowledge of investment products lead many people decided not to invest for their future. This can be overcome by utilizing the information and communication technology development by making a web application of Smart Investment Planner with the aim to recognize various types of investment product as well as the character investment and tips for users. This application uses a set of data as knowledge base which obtained from the literature, discussions with economic experts, database design, user interface design, as well as tests and evaluations by experts. The result of these applications concluded that this application collect the information as well as investment products that suit into their needs and also encourage them to start invest.
\end{abstract}

Keyword: investment, application, web

\begin{abstract}
ABSTRAK
Minimnya pengetahuan akan produk investasi membuat banyak kalangan masyarakat memutuskan untuk tidak melakukan investasi bagi masa depan mereka. Lalu dengan adanya latar belakang masalah tersebut dibuat aplikasi smart investment planner berbasis web dengan tujuan untuk mengenal serta mencari kecocokan dengan berbagai jenis produk investasi beserta informasi dan tips bagi pengguna. Metode yang digunakan dalam pembuatan aplikasi ini adalah pengumpulan data melalui wawancara, teknik kepustakaan, membuat perancangan basis data, tampilan, serta ujicoba dan evaluasi oleh pakar. Hasil pengujian menyimpulkan aplikasi ini dapat membantu pengguna menemukan produk investasi yang sesuai dengan mereka.
\end{abstract}

Kata kunci: investasi, aplikasi, web 


\section{PENDAHULUAN}

Investasi pada hakikatnya merupakan penempatan sejumlah dana pada masa sekarang dengan harapan dapat menghasilkan keuntungan pada masa mendatang. Tujuan investor melakukan kegiatan investasi adalah untuk mendapatkan keuntungan yang akan diperoleh pada masa mendatang. Jenis investasi dibagi menjadi dua yaitu investasi aktif dan investasi pasif, investasi aktif merupakan investasi yang membutuhkan campur tangan investor dalam pengelolaannya sedangkan investasi pasif merupakan jenis investasi yang tidak membutuhkan campur tangan investor dalam pengelolaannya karena akan dikelola oleh manajer investasi atau investasi akan bergerak naik dengan sendirinya (Sawidji, 2008).

Secara umum jenis investasi dibagi menjadi dua jenis yaitu real asset dan financial asset. Real asset merupakan jenis investasi atau aktiva yang disimpan dalam produk nyata seperti logam mulia, valuta asing, dan property. Sedangkan financial asset merupakan aktiva yang berbentuk surat-surat berharga seperti saham, reksadana, dan obligasi. Pengetahuan masyarakat yang minim mengenai investasi dan keinginan mendapatkan return atau keuntungan yang tinggi membuat sebagian besar masyarakat tertipu dengan investasi bodong.

Ada beberapa hal penting yang perlu diperhatikan para calon investor sebelum menginvestasikan modal yang mereka miliki. Pertama adalah menentukan modal yang akan dialokasikan untuk investasi setelah mengetahui modal yang dimiliki, dapat diketahui tolak ukur modal yaitu berupa modal kecil atau besar. Selanjutnya, sebaiknya ditentukan latar belakang atau tujuan investasi karena setiap orang memiliki karakter serta tujuan investasi yang berbeda-beda (Adhitya dan Gusti, 2013). Pengetahuan dasar yang minim dalam berinvestasi merupakan faktor utama penyebab penipuan berkedok investasi seperti yang dikemukakan oleh Otoritas Jasa Keuangan (OJK) (Nurul, 2014). Menurut hasil penelitian dari World Bank pendapatan per kapita Indonesia meningkat dari US\$1.900 pada tahun 2007 menjadi US\$3.500 di tahun 2012. Peningkatan pendapatan ini mempengaruhi pola keuangan tiap individu di Indonesia namun penetrasi produk investasi di Indonesia masih di bawah 20\% (Bismo, 2014).

Bank Indonesia mencatat pertumbuhan inflasi pada januari 2014 sebesar 8,22\% (Bank Indonesia, 2014). Hal ini perlu diwaspadai oleh masyarakat bahwa nilai mata uang yang disimpan akan menurun setiap tahun, oleh karena itu sebaiknya masyarakat dapat mulai melakukan investasi untuk jangka waktu kedepan. Pengetahuan masyarakat yang minim mengenai investasi serta keinginan mendapatkan keuntungan tinggi membuat masyarakat terjebak dengan penipuan berkedok investasi. Pada agustus 2014 OJK mencatat adanya 750 perusahaan investasi penipu (Chadiza, 2014). Maraknya penipuan investasi membuat sebagian besar masyarakat ragu untuk berinvestasi.

Salah satu cara untuk mengetahui investasi yang cocok adalah dengan mengetahui kemampuan keuangan serta berbagai faktor pendukung lain serta berkonsultasi dengan para konsultan ekonomi. Seringkali para konsultan ekonomi sulit untuk ditemui dan untuk berkonsultasi membutuhkan biaya yang cukup besar, ini yang membuat para calon investor pemula enggan untuk berkonsulasi dengan para konsultan. Penyebab lain keengganan calon investor untuk berkonsultasi adalah keterbatasan jarak dan waktu untuk mendapatkan seorang konsultan ekonomi. Berdasarkan latar belakang masalah yang telah dikemukakan, bagaimana cara mengetahui produk investasi yang sesuai dari variabel serta ciri yang sesuai dengan pengguna?

Perancangan aplikasi smart investment planner meliputi: (1) Materi jenis investasi pada smart investment planner ini hanya terdiri dari produk investasi pasif yang umum digunakan oleh para investor pada saat ini seperti tabungan, deposito, emas, properti, saham, reksadana, obligasi, valuta 
asing, dan asuransi unit link. (2) Aplikasi smart investment planner menggunakan server XAMPP sebagai basis data. (3) Aplikasi ini dapat dijalankan dalam web browser dengan koneksi internet.

Tujuan dari merancang sebuah aplikasi berbasis web yang dapat membantu pengguna menemukan jenis investasi yang paling sesuai dengan mereka dari Sembilan jenis investasi yang terdapat dalam aplikasi smart investment planner. Sedangkan manfaat yang diperoleh dari penelitian ini adalah menyampaikan informasi serta edukasi dari seorang pakar ke dalam aplikasi smart investment planner serta pengguna memperoleh informasi dari pemikiran pakar mengenai jenis investasi yang sesuai dengan dirinya.

\section{METODE}

Perancangan aplikasi smart investment planner ini dilakukan dengan menggunakan beberapa tahapan: (1) Studi Pustaka yaitu mempelajari buku, jurnal, dan artikel atau sumber ilmiah tertulis lainnya untuk memperkuat teori dan pengetahuan dalam penyelesaian penelitian. (2) Wawancara Pakar yaitu mendiskusikan hasil pengamatan dan berbagai teori dengan para pakar, meminta masukkan dan pendapat dari pakar mengenai variabel yang telah ditentukan, dan meminta bantuan dari pakar untuk menentukan pertanyaan yang akan diajukan pada pengguna.

\section{HASIL DAN PEMBAHASAN}

Proses akusisi pengetahuan meliputi perancangan tabel basis pengetahuan dalam basis pengetahuan serta proses penalaran aplikasi dan hubungan tabel di dalam basis data. Adapun tabel basis pengetahuan yang ada adalah sebagai berikut seperti pada tabel 1. Tabel tersebut berisi berbagai ciri karakter dalam berinvestasi dengan hubungan terhadap jenis investasi. Sebelum pengguna diajukan pertanyaan yang ada pada basis pengetahuan, maka pengguna diwajibkan untuk mengisi variabel utama yang berisi modal, jangka, resiko, dan likuiditas. Isi dari empat faktor tersebut akan mengarahkan pertanyaan mana yang akan ditanyakan kepada pengguna, selanjutnya jawaban pengguna akan dicocokan dengan rule yang berlaku dalam aplikasi.

Tabel 1 Tabel Basis Pengetahuan

\begin{tabular}{cl}
\hline Jenis Investasi & \multicolumn{1}{c}{ Basis Pengetahuan } \\
\hline \multirow{2}{*}{ Tabungan } & $\begin{array}{l}\text { IF Belum memiliki investasi sebelumnya OR Sering memiliki kebutuhan mendesak OR } \\
\text { belum memiliki dana darurat (ideal } 6 \text { kali dari penghasilan) THEN Tabungan }\end{array}$ \\
& IF Membutuhan investasi dengan tingkat keamanan tinggi AND Tidak masalah dengan \\
Deposito & $\begin{array}{l}\text { return minim THEN Deposito ELSE IF Membutuhkan investasi dengan jaminan LPS } \\
\text { (pemerintah) THEN Deposito }\end{array}$ \\
& IF Memiliki tempat untuk menyimpan aset dengan aman OR Membutuhkan investasi yang \\
& dapat diagunkan THEN Emas \\
& IF Sering bepergian ke luar negeri AND Memiliki tempat untuk menyimpan aset dengan \\
Valuta Asing & aman THEN Valuta Asing ELSE IF Memiliki instrumen investasi lain OR Memiliki \\
& pengetahuan seputar transaksi marginTHEN Valuta Asing \\
& IF Memiliki pengetahuan seputar legalitas dokumen AND Memiliki perencanaan matang \\
& ketika membeli / menjual aset THEN Properti ELSE IF Bersedia dengan biaya pajak dan \\
& maintenance berkala OR Membutuhkan investasi yang dapat diagunkan THEN Properti \\
& IF Memiliki pengetahuan seputar ekonomi AND Memiliki analisa keuangan yang baik \\
& THEN Saham ELSE IF Tidak mudah dipengaruhi oleh berita atau isu dalam membuat \\
& keputusan THEN Saham
\end{tabular}


Tabel 1 Tabel Basis Pengetahuan (Lanjutan)

\begin{tabular}{cl}
\hline Jenis Investasi & \multicolumn{1}{c}{ Basis Pengetahuan } \\
\hline \multirow{3}{*}{ Reksadana } & $\begin{array}{l}\text { IF Tidak memiliki waktu dan pengetahuan untuk mengelola investasi } \\
\text { AND Membutuhkan bantuan pihak ketiga untuk mengatur investasi THEN Reksadana } \\
\text { ELSE IF Tidak menguasai teknik portofolio investasi THEN Reksadana }\end{array}$ \\
$\begin{array}{l}\text { Obligasi } \\
\text { IF Memiliki pengetahuan seputar ekonomi AND Memiliki perencanaan ekonomi jangka } \\
\text { panjang THEN Obligasi }\end{array}$ & $\begin{array}{l}\text { IF Membutuhkan proteksiOR Tidak terbeban dengan investasi secara berkala THEN Unit } \\
\text { Link }\end{array}$ \\
\hline
\end{tabular}

\section{Analisa}

Merupakan proses penentuan variabel utama dalam aplikasi smart investment planner untuk menentukan jenis investasi yang akan sejalan dengan pemikiran para pakar dan studi literatur yang telah dilakukan. Dalam pengembangan aplikasi smart investment planner cara kerja aplikasi pada bagian menu planner aplikasi akan mewajibkan pengguna untuk mengisi variabel utama yang akan membantu sistem menentukan investasi yang paling sesuai berdasarkan basis pengetahuan pada pengguna. Variabel utama dalam investasi meliputi modal, jangka waktu investasi, resiko investasi, dan likuiditas aset.

Setelah pengguna memasukkan variabel sesuai dengan keadaan mereka, maka sistem akan memberikan pilihan profil investor terhadap pengguna, bagi pengguna yang sudah memiliki pengetahuan investasi maka pengguna dapat memilih beberapa jenis investasi yang dikeluarkan sistem untuk ditanyakan oleh sistem, hal ini bertujuan untuk memberikan pilihan bagi pengguna yang sudah memiliki pengetahuan agar dapat memilih jenis investasi yang mereka sukai saja. Selain itu bagi pengguna yang belum memiliki pengetahuan investasi maka sistem akan menanyakan seluruh karakter investasi yang sesuai dengan variabel dari pengguna.

Sistem aplikasi selanjutnya akan memberikan pertanyaan berupa karakter dalam berinvestasi yang harus dijawab oleh pengguna, adapun jawaban yang dapat dipilih oleh pengguna berupa jawaban Ya dan Tidak, setelah menjawab seluruh pertanyaan maka sistem akan memberikan output mengenai jenis investasi yang sesuai dengan pengguna dari Sembilan aplikasi yang terdapat dalam basis pengetahuan.

\section{Desain}

Pada tahap ini akan dilakukan beberapa rancangan sebelum membuat aplikasi seperti membuat rancangan tampilan, perancangan basis data. Dalam merancang aplikasi smart investment planner dilakukan perancangan sistem terlebih dahulu agar aplikasi yang dibuat dapat terstruktur secara sistematis dengan baik. Adapula perancangan sistem terhadap aplikasi adalah sebagai berikut: 


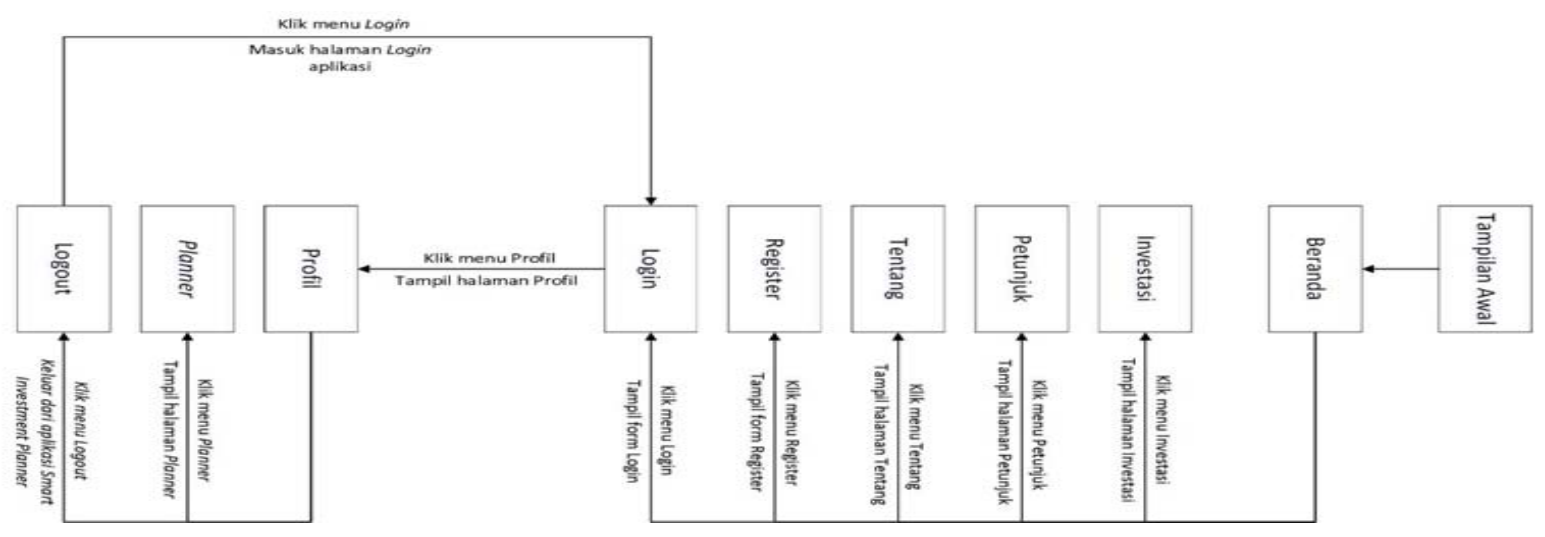

Gambar 1 Diagram Transisi Aplikasi Smart Investment Planner

Diagram transisi merupakan suatu media perancangan yang pada umumnya digunakan untuk menggambarkan keadaan sebuah sistem. Diagram transisi aplikasi smart investment planner seperti yang terdapat pada Gambar 1. Pada bagian awal pengguna akan masuk pada bagian beranda yang dapat mengarahkan pada menu investasi, petunjuk, tentang. Serta pada halaman beranda pengguna juga dapat melakukan register atau login. Bagi pengguna yang sudah melakukan login, dapat mengakses menu profil, melakukan diagnosa planner.

Pada menu profil pengguna dapat mengedit profil mereka yang telah mereka daftarkan pada saat registrasi hingga merubah password akun dan melihat histori record planner mereka. Selain itu bagi pengguna yang telah melakukan log in dapat mengakses menu planner yang dapat membantu pengguna menemukan jenis investasi yang paling sesuai dengan mereka dari basis pengetahuan yang ada. Pengguna yang telah melakukan login juga dapat mengakses menu investasi, petunjuk, tentang, dan melakukan logout dari aplikasi.

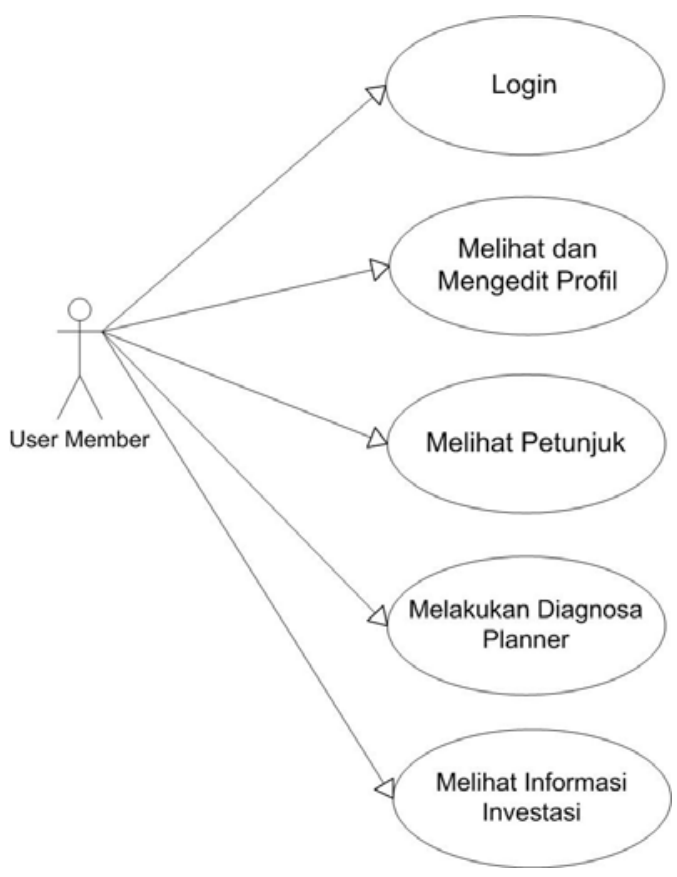

Gambar 2 Use Case Diagram Pengguna Terdaftar 
Pada gambar 2 terdapat use case diagram pengguna terdaftar yang menggambarkan interaksi antara pengguna terdaftar dengan sistem yang dapat melakukan login, melihat dan mengedit profil, melihat petunjuk, melakukan diagnose planner, serta melihat informasi investasi. Setelah melakukan perancangan diagram transisi dan use case diagram maka rancangan layar dari aplikasi smart investment planner digambarkan. Adapun gambaran rancangan layar dari aplikasi adalah sebagai berikut.

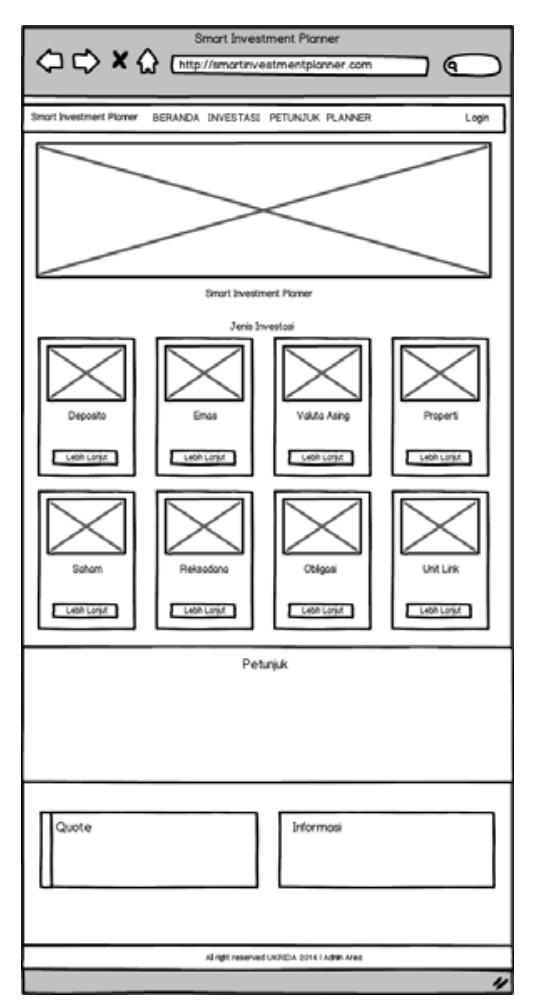

Gambar 3 Rancangan Halaman Beranda

Gambar 2 merupakan rancangan halaman utama dari aplikasi smart investment planner. Dalam rancangan tampilan halaman beranda ini terdapat beberapa bagian, yaitu: (1) Menu Navigasi, digunakan untuk mengakses halaman dalam web. (2) Image Slider, yang berisi berbagai gambar pendukung investasi. (3) Jenis Investasi, berisi penjelasan singkat mengenai berbagai jenis investasi dalam web.Terdapat tombol lebih lanjut yang akan menampilkan penjelasan mengenai investasi lebih lengkap. (4) Petunjuk, berisi petunjuk penggunaan aplikasi smart investment planner. (5) Quote, berisi quotes dari para pakar investasi. (6) Informasi, berisi informasi mengenai aplikasi smart investment planner. (7) Login, berisi dropdown form yang dapat digunakan pengguna untuk melakukan login atau registrasi.

Aplikasi smart investment planner menggunakan basis data sebagai sarana penyimpan pengetahuan, data, serta informasi investasi. Basis data aplikasi terdiri dari 15 buah tabel yang terdiri dari tabel penjelas, investasi, member, rule, quote, thumbartikel, admin, cirikhusus, record_inv, record_cirikhusus, record, relasi, jawaban, slider, dan gambar. Berikut merupakan entity relationship diagram yang akan merepresentasi setiap entitas yang memiliki atribut dan terhubung dengan entitas lainnya dalam basis data. Dalam perancangan basis data aplikasi, username pada tabel member memiliki hubungan one to many dengan kdmember pada tb_jwb, tb_record_inv, tb_record_cirikhusus, dan tb_record. Hal ini karena sebuah gambar hanya memiliki relasi dengan sebuah ciri khusus. Selain itu pada tb_penjelas juga memiliki hubungan one to one dengan tb_investasi seperti gambar berikut. 


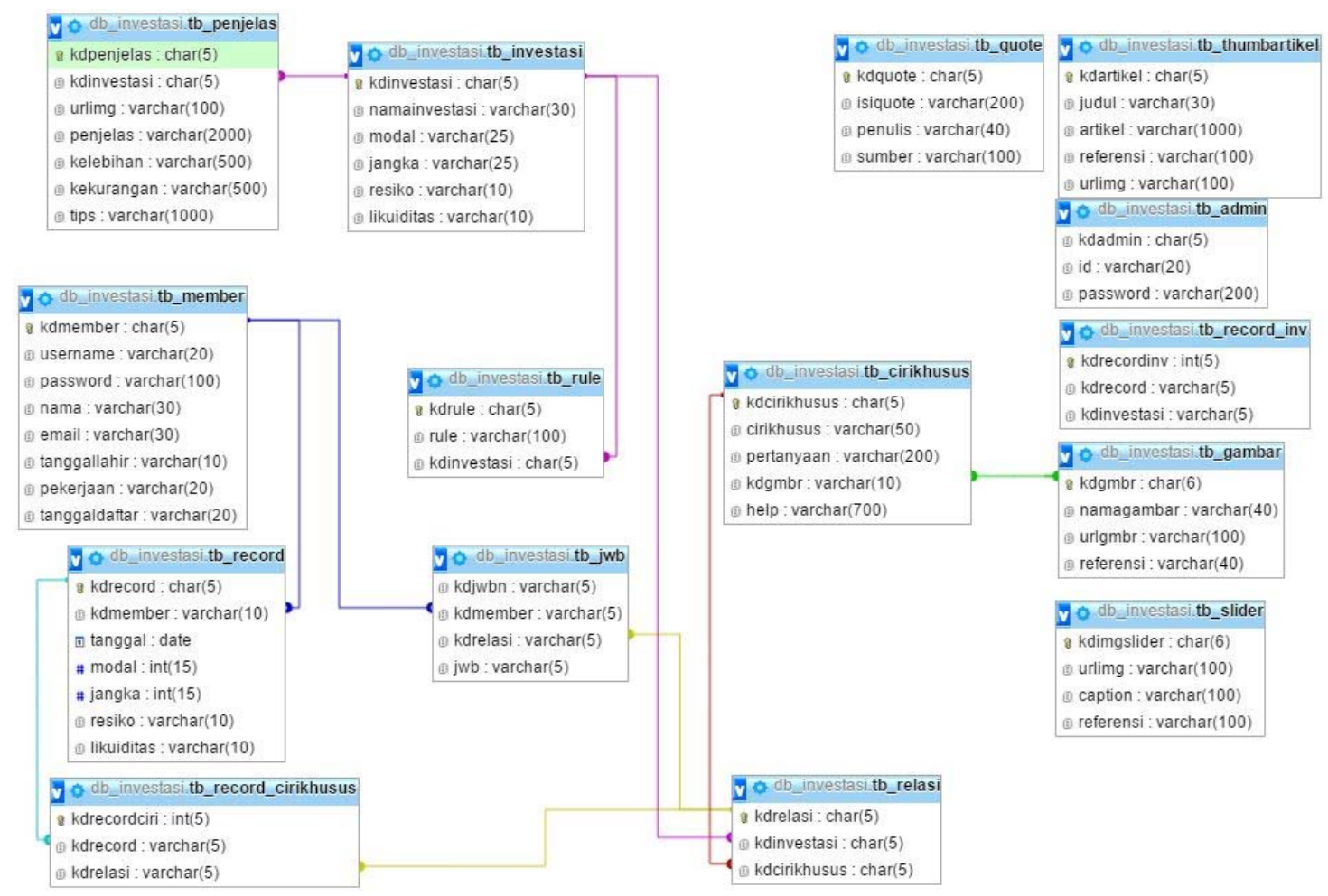

Gambar 4 Entity Relationship Diagram Aplikasi Smart Investment Planner

\section{Implementasi}

Setelah dilakukan implementasi aplikasi smart investment planner secara detail dapat dilihat pada www.smartplanner.web.id . Adapun tampilan layar beranda aplikasi dapat dilihat pada gambar 5 . Dalam halaman beranda terdapat bagian navigasi menu yang akan mengarahkan pada halaman selanjutnya seperti investasi, petunjuk, tentang, diagnose planner, serta login untuk pengguna yang ingin melakukan login serta melakukan sign up bagi pengguna yang belum terdaftar. Untuk melakukan diagnose planner maka pengguna diharuskan untuk login terlebih dahulu. Pengguna dapat login melalui login dropdown form yang akan muncul setelah pengguna mengakses menu login.

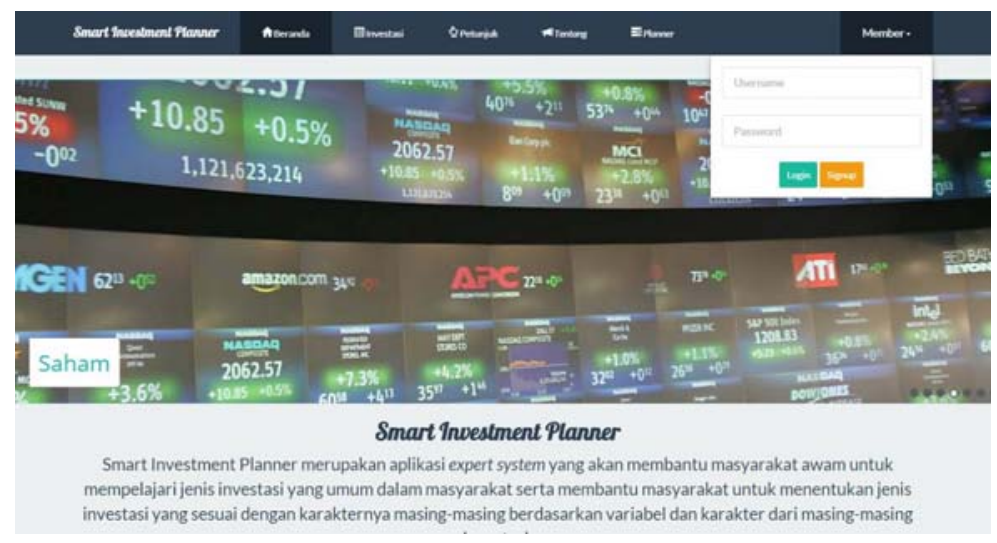

Gambar 5 Tampilan Layar Halaman Beranda 
Setelah pengguna melakukan diagnosa jenis investasi maka selanjutnya akan muncul hasil kesimpulan berupa jenis investasi yang sesuai dengan pengguna berdasarkan variabel utama serta jawaban yang telah dimasukan oleh pengguna. Pada bagian akhir pengguna akan diberikan ringkasan antara variabel serta pernyataan yang telah dijawab pada bagian sebelumnya, selanjutnya akan terdapat beberapa jenis investasi yang sesuai dengan data yang diberikan oleh pengguna. Investasi yang akan muncul berbentuk thumbnail disertai gambar beserta kelebihan dan kekurangan dari investasi, juga dilengkapi tombol lebih lanjut apabila pengguna ingin melihat penjelasan investasi lebih lengkap seperti pada gambar 6 .

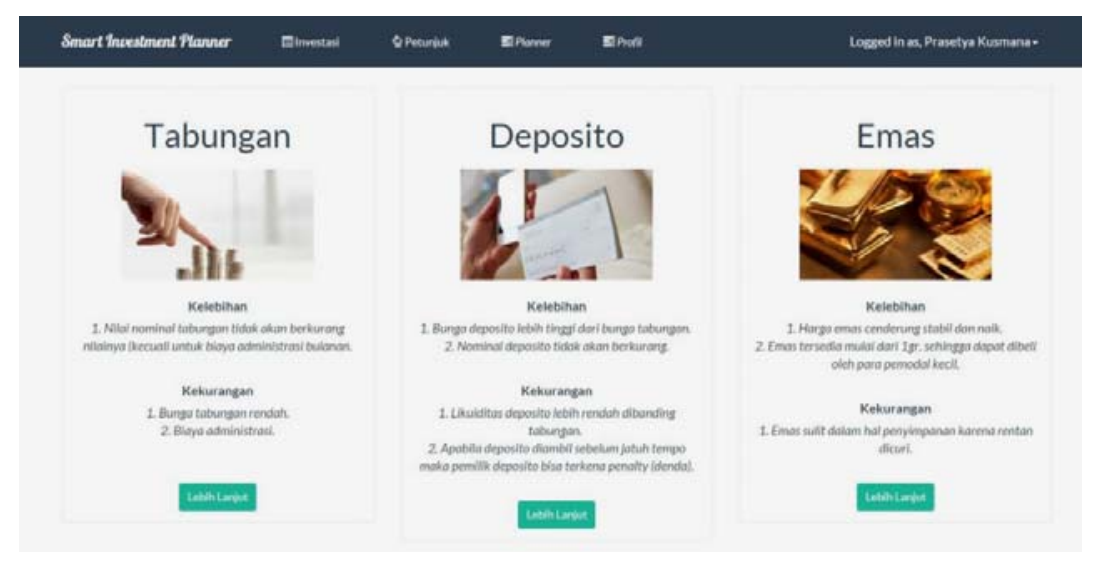

Gambar 6 Tampilan Layar Hasil

Dari kuesioner yang telah disebar kepada 55 responden yang telah menggunakan aplikasi smart investment planner tercatat data sebagai berikut seperti pada Gambar 7 di bawah ini.

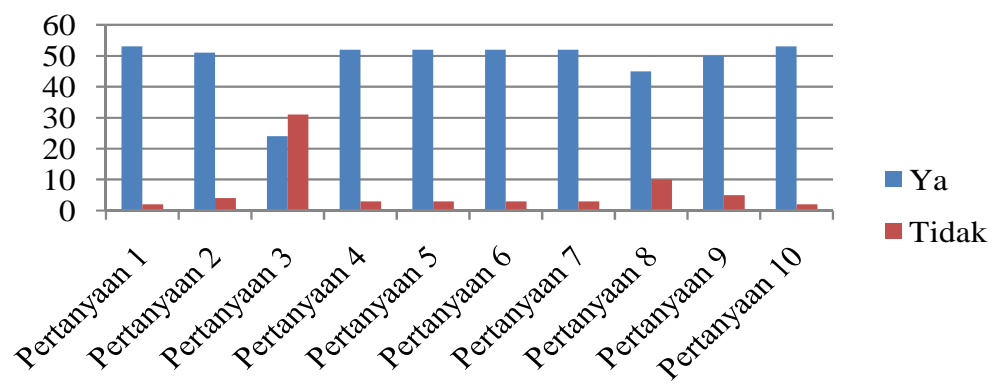

Gambar 7 Hasil Kuesioner Pengujian Aplikasi

\section{Pertanyaan 1}

Apakah dengan adanya aplikasi smart investment planner anda dapat mengenal dan mendapatkan informasi yang jelas mengenai berbagai produk investasi?

\section{Pertanyaan 2}

Apakah anda dapat dengan mudah menggunakan fitur yang ada pada aplikasi smart investment planner termasuk menu planner yang dapat membantu anda menentukan produk investasi yang tepat? 


\section{Pertanyaan 3}

Apakah sebelumnya anda sudah memiliki pengetahuan seputar investasi baik mengenai karakter, kelebihan, serta kekurangan masing-masing investasi?

\section{Pertanyaan 4}

Apakah anda dapat memahami konten, penjelasan, instruksi, pertanyaan, serta bantuan yang ada pada aplikasi ini?

\section{Pertanyaan 5}

Apakah aplikasi smart investment planner membantu anda dalam menemukan produk investasi yang sesuai dengan diri anda?

\section{Pertanyaan 6}

Apakah penjelasan serta tips yang diberikan oleh aplikasi smart investment planner membantu anda dalam penerapan memilih produk investasi anda di masa mendatang?

\section{Pertanyaan 7}

Apakah tampilan aplikasi smart investment planner menarik dan mudah digunakan?

\section{Pertanyaan 8}

Setelah menggunakan aplikasi smart investment planner, apakah anda mulai tertarik untuk berinvestasi dengan tujuan memenuhi kebutuhan finansial pada masa mendatang?

\section{Pertanyaan 9}

Menurut anda, apakah aplikasi smart investment planner dapat membantu engedukasi masyarakat agar tidak mudah tertipu investasi bodong?

\section{Pertanyaan 10}

Menurut anda, apakah aplikasi ini perlu dikembangkan kembali pada masa mendatang? Berdasarkan data yang dihimpun dari 55 responden, yaitu masyarakat yang berminat untuk berinvestasi, dapat ditarik suatu kesimpulan bahwa aplikasi ini dapat berjalan optimal sesuai dengan fungsinya sebagai aplikasi yang dapat membantu pengguna dalam menemukan jenis investasi.

\section{SIMPULAN}

Berdasarkan hasil penelitian dan pembahasan yang telah dilakukan, aplikasi ini dapat digunakan dengan mudah serta memiliki dampak positif terhadap para responden yaitu menjadi lebih berminat untuk melakukan investasi. Pada aplikasi ini juga terdapat informasi dari pakar yang sudah diakusisi. Menurut pakar, aplikasi ini sudah dapat merepresentasikan pola pikir pakar dalam mengambil keputusan produk investasi yang sesuai dengan pengguna. Maka dapat disimpulkan bahwa aplikasi smart investment planner ini cukup membantu masyarakat awam dalam menemukan produk investasi yang sesuai dengan variabel mereka. Setelah menemukan produk investasi yang sesuai selanjutnya pengguna juga akan mendapatkan informasi, karakter, serta tips yang dapat mereka terapkan dalam melakukan investasi. 


\section{DAFTAR PUSTAKA}

Adhitya, I., Gusti, N. (2013). Perbandingan Berinvestasi Antara Logam Mulia Emas dengan Saham Perusahaan Pertambangan Emas. Bali: Fakultas Ekonomi Univesitas Udayana.

Bank Indonesia. (2013). Data Inflasi. Bank Indonesia. Diakses dari http://www.bi.go.id/id/moneter/inflasi/data/Default.aspx;

Bismo, M. (2013). Pengetahuan Investasi Wajib Dimiliki Seiring Pendapatan Per Kapita. Berita Satu Online. Diakses pada 22 September 2014, dari http://www.beritasatu.com/bank-danpembiayaan/148818-pengetahuan-investasi-wajib-dimiliki-seiring-pendapatan-per-apita.html

Sawidji. (2008). Professional Investing. Jakarta: Elex Media Komputindo.

Lathiffah, N. (2013). OJK Akui Masyarakat Minim Edukasi Investasi. Neraca. Diakses pada 21 September 2014, dari http://www.neraca.co.id/article/26341/OJK-Akui-Masyarakat-MinimEdukasi-Investasi

Syafina, C. D. (2014). OJK: Ada 750 Perusahaan Investasi Bodong. Kontan Online, Diakses pada 24 September 2014 dari http://investasi.kontan.co.id/news/ojk-ada-750-perusahaan-investasibodong 